\title{
Genetic parameters for earlywood and latewood densities and development with increasing age in Scots pine
}

\author{
Anders FRIES $^{1 *}$, Tore ERICSSON ${ }^{2}$ \\ ${ }^{1}$ Department of Forest Genetics and Plant Physiology, Swedish University of Agricultural Sciences, 90183 Umeå, Sweden \\ ${ }^{2}$ Skogforsk, Box 3, 91821 Sävar, Sweden
}

(Received 11 July 2008; accepted 25 November 2008)

\author{
Keywords: \\ wood density / \\ growth / \\ heritability / \\ genetic correlation / \\ Pinus sylvestris
}

\begin{abstract}
- Each annual ring in pines consists of earlywood and latewood with considerable difference in density and width. To get a better determination of the genetic regulation of total wood density in Scots pine (Pinus sylvestris L.), density and width of those ring sections were measured in annual ring numbers 12 to 21 of Scots pines in a full-sib progeny test. Tree height and stem diameter were also measured.

- Heritabilities for the annual ring sections increased with age for earlywood density from 0.08 to approximately 0.25 ; latewood density showed similar reductions. Heritability over all 10 annual rings was 0.25 for earlywood density, 0.22 for latewood density, 0.29 for height and 0.10 for stem diameter. Genetic correlations between earlywood and latewood density and growth traits were negative, while they were strongly positive between densities of adjacent annual rings (0.70-1.0).

- Despite the higher heritability of earlywood density, the strong positive genetic correlation between those traits indicates little benefit from focusing solely on earlywood density when selecting for wood density. Analysing earlywood and latewood separately does not benefit from including the width of the corresponding ring section as a covariate. Juvenile wood may possibly turn into mature wood 15-20 y from the pith.
\end{abstract}

Résumé - Paramètres génétiques pour les densités du bois initial et du bois final et évolution avec l'âge chez le pin sylvestre.

- Chaque cerne annuel chez les pins est composé de bois initial et de bois final avec une différence de densité et de largeur. Pour obtenir une meilleure détermination de la régulation génétique de la densité totale de bois chez le pin sylvestre (Pinus sylvestris L.), la densité et la largeur de ces sections de cernes annuels ont été mesurées chez 12 à 21 pins sylvestres dans un essai de descendance de plein frères. La hauteur des arbres et le diamètre des troncs ont également été mesurés.

- Les héritabilités pour les sections de cernes annuels augmentent avec l'âge pour la densité du bois initial de 0,08 à environ 0,25 ; la densité du bois final a montré des réductions similaires. L'héritabilité sur l'ensemble de 10 cernes a été de 0,25 pour la densité du bois initial, de 0,22 pour la densité du bois final, de 0,29 pour la hauteur et de 0,10 pour diamètre du tronc. Les corrélations génétiques entre densité du bois initial et du bois final et caractéristiques de la croissance ont été négatives, alors qu'elles ont été fortement positives entre la densité des cernes adjacents $(0,70-1,0)$.

- Malgré la plus forte héritabilité de la densité du bois initial, la forte corrélation génétique entre ces caractéristiques montre qu'il y a peu d'intérêt à se concentrer uniquement sur la densité du bois initial lors de la sélection pour la densité du bois. Analyser bois initial et bois final séparément ne bénéficie pas de l'inclusion comme covariable de la largeur de la section du cerne correspondant. Le bois juvénile peut devenir à son tour du bois adulte, 15-20 ans à partir de la moelle.

\section{INTRODUCTION}

To date, forest tree breeding in Sweden has focused on increasing volume production while maintaining low mortality through producing trees that are well adapted to the current

\footnotetext{
* Corresponding author: anders.fries@genfys.slu.se
}

environment and conditions predicted for the future. In order to obtain high saw timber quality, stem straightness and branch quality have also been included in the selection criteria. However, it is not known whether the predicted improvement in volume through breeding is accompanied by a decrease in wood density, which could lead to reduced improvement in 
amount of wood biomass. The present study evaluates wood density measurements in a progeny test with full-sib families from controlled crosses between plus tree clones growing in production seed orchards. It should thus provide important information about the total effect of the breeding improvement on the production of wood biomass, and provide genetic parameters that could be used if wood density is included in the selection criteria in future breeding programmes.

The wood of a Scots pine tree is very heterogeneous. It is composed of a series of radial annual rings, each of which includes both earlywood and latewood, and a transition zone between those wood types. The cell structure of earlywood and latewood is rather different and this affects the density. Earlywood cells are wide, and have a squared cross-section and thin walls, while the latewood cells have thicker walls and are radially compressed. Thus, their lumens are smaller (Hodge and Purnell, 1993), and they therefore have more wood mass per unit volume, giving the latewood higher density than the earlywood. On the other hand, latewood sections are normally considerably thinner than earlywood sections. It has been claimed by Evans et al. (1995) that the expansion of fibre cells occurs over a different time scale from cell wall formation, and that these processes may, therefore, be regulated by different genes. If so, it may be possible to obtain annual rings and ring sections with large diameter and cells with thick walls, resulting in both high wood density and wide annual rings. In addition, earlywood continues to be formed until shoot elongation stops, at which point latewood formation commences and continues until cambial growth ceases in late summer (VargasHernandez and Adams, 1994). Thus, cambial phenology - especially the length of the latewood formation period, which is a genetically regulated trait (Vargas-Hernandez and Adams, 1994) - is important for determining the relative amount of latewood in an annual ring and, hence, the whole ring density, but not necessarily the latewood density per se. The density of the whole ring is thus also genetically influenced through the genetic factors affecting cambial phenology. Due to annual variations in growth conditions and, thus, growth rhythms, radial growth must be broken down to the level of annual growth ring sections. Since more of the extra radial growth in a favourable year is laid down in the earlywood with lower wood density than the latewood (Zamudi et al., 2005), the overall density of the annual ring formed in a favourable year should be lower than in a year when conditions are poor; the latter should result in a larger fraction of high-density latewood. The main argument for a growth rate compensation in evaluations is thus the altered relation between the earlywood and latewood width. The width or the area of the growth ring is hence often used as a covariate, e.g. in Hodge and Purnell (1993), Hannrup et al. (2000), Li and Wu (2005), and Fries and Ericsson (2006). The hypothesis tested in the present study is, thus, that if earlywood density and latewood density are analysed separately there is no need to take account of the width of each of the wood types. Analysing the wood types separately should increase the scope for accurately estimating wood densities, their genetic parameters, and exploring possible genetic relationships between growth rates and earlywood and latewood densities.
In most conifers, there is a transition between juvenile wood and mature wood some distance from the pith. Some authors, e.g. Burdon et al. (2004), refer to this as a change from corewood to outerwood, and use the change from juvenile wood to mature wood to describe the vertical differences in wood types. Cown (1992) also discusses these definitions. However, in the present paper the terms juvenile and mature wood refer to the radially differentiated wood types. In pines (Pinus spp.), juvenile wood is characterised by shorter tracheids with thinner walls and hence lower density than mature wood (Zobel and Sprague, 1998). Actually, Cown (1992) suggests using wood density to define the boundary between juvenile and mature wood. Furthermore, juvenile wood has microfibrils oriented at a larger angle to the long cell axis (higher microfibril angle), a trait of considerable importance in the pulping process and in the paper properties of the resultant pulp, as well as affecting wood stiffness (Couchene et al., 2006; Steffenrem et al., 2008). The change from juvenile wood to mature wood is generally claimed to occur at around 15 annual rings from the pith in pines and Norway spruce (see Burdon et al., 2004; Kučera, 1994), although Zamudi et al. (2005) set the threshold for Pinus radiata at around ring number 10 . It is generally desirable to evaluate progeny tests at as young an age as possible, but this is in conflict with evaluating mature wood density. One aim of the work described herein was to examine the development of wood density during the 10-year period encompassing the suggested transition from juvenile wood to mature wood, and to determine whether juvenile wood density is genetically correlated with mature wood density. This should increase the potential for using juvenile wood density to predict high mature wood density.

The specific objectives of the present study were thus:

- to estimate genetic parameters for earlywood and latewood density separately, and for individual years, and to assess the effect of including the width of the corresponding wood types in the estimation;

- to estimate the genetic correlations between the densities of the different wood types, between different years, and between densities and growth traits; and

- to follow the development of earlywood and latewood density during the years proposed for the transition from juvenile to mature wood.

The whole ring wood density of the same material was evaluated in a previous study (Fries and Ericsson, 2006).

\section{MATERIAL AND METHODS}

\subsection{Progeny test plantation, data collection and sample treatment}

The present study examines wood samples of full-sib progenies of plus trees in the Swedish Scots pine breeding programme for use in northern Sweden. The progeny test, Grundtjärn (S23F711261, at 63 $33^{\prime} \mathrm{N}, 17^{\circ} 25^{\prime} \mathrm{E}$ and $320 \mathrm{~m}$ elevation), includes 197 full-sib families from controlled crosses of 50 phenotypically selected first-generation parents. The plus tree parents were regarded as a random sample 
from a population of plus trees. The crossing scheme layout was a partial diallel, approximating Kempthorne and Curnow's (1961) circulant design, with each parent being either mother or father eight times (for eight parents, nine times). For further details of the layout, see Fries and Ericsson (2006).

The study evaluates the density of the earlywood and latewood separately in annual ring numbers ca. 12-21 from the pith (see Fries and Ericsson (2006) for a description of the determination of the annual ring numbers). Determining ring number from the bark inwards, as in this study, relates only approximately to counting from the pith, since different trees attain breast height at somewhat different ages. On the other hand, using this method ensures that the same ring numbers equate to formation during the same calendar year. The wood samples used in the analyses were increment cores with a diameter of approximately $5 \mathrm{~mm}$, collected in September 2001 from trees 30 growing seasons since planting (32 growing seasons from seed). The cores were taken from the bark to, or almost to, the pith, amounting to 18-26 annual rings. The south-west area of the progeny test was the subject of the study, and the wood samples were collected from 2640 trees (54\%) in the experimental plantation. Only undamaged or slightly damaged trees were used. At the same time the total height and stem diameter of the trees were measured, and their vitality was assessed. Wood density was measured by X-ray diffraction using an Itrax Density Scanner (Cox Analytical Systems, http:// www.coxsys.se/itrax_density_scanner.htm). This device is described in more detail in Lindeberg (2001) and Bergsten et al. (2001), and in Fries and Ericsson (2006) the procedure followed is described in detail.

The Itrax analyser creates photographic exposures of the core; these are used to manually determine the border between each annual ring, while the earlywood/latewood-boundary was automatically set at $50 \%$ of the maximum density for that ring. Absorption values were translated into wood densities in the increment cores using a density reference stick, which was included in each run (one run comprised 19 samples plus the reference).

\subsection{Treatment of the data}

Out of the 2640 trees from which wood sample increment cores were taken, 1655 (63\%) yielded exposures which produced acceptable data. Based on visual examination, there were three main reasons for not accepting the photo exposures or the resulting data: (i) difficulties in identifying the boundaries between annual rings since the annual rings were extremely narrow, the increment cores were broken or not sufficiently straight; (ii) the photo exposure was not of sufficient quality because the camera was accidentally out of position during the X-ray analyses; and (iii) the angle of the annual ring in the strip differed too much from the perpendicular in comparison with the long axis of the stick. Single annual rings with compression wood and cracks were also excluded.

\subsection{Genetic model and statistical analysis}

The analyses were conducted using ASReml 2.0 statistical software (Gilmore, 2006), and a parent-term setup was fitted to the data in order to be applicable to the genetic model $P=A+E$ with corresponding variances $\sigma_{P}^{2}=\sigma_{A}^{2}+\sigma_{E}^{2}$ to be estimated. In this model $P$ is the phenotypic value, $A$ the additive genetic effect, and $E$ the assumed independent environmental effect including any genetic residual. Block effects were included as a fixed effect and parent effects as random components. Furthermore, most analyses were undertaken both with and without the width of the corresponding annual ring section as a covariate, i.e. for earlywood density of annual ring 12 the width of the earlywood of annual ring 12 was used, etc. When estimating the correlations between different years no covariate could be used since multiple years were involved.

The random components in the genetic model were constructed based on a parent design matrix giving the relationships of the full-sib families. As for the variances above, the covariances were assumed to be composed as follows:

$$
\sigma_{P_{i j}}=\sigma_{A_{i j}}+\sigma_{E_{i j}}
$$

for the traits $i$ and $j$.

The variances and covariances (and/or corresponding correlations) were estimated using the REML method in the ASReml runs (which also yield BLUP breeding values), and they formed the basis for deriving estimates of heritability and genetic correlations. The complete genetic model is presented in Fries and Ericsson (2006).

\section{RESULTS}

Latewood density (LD) was more than twice as high as earlywood density (ED): $0.7-0.8 \mathrm{~g} \cdot \mathrm{cm}^{-3}$ compared with ca. $0.35 \mathrm{~g} \cdot \mathrm{cm}^{-3}$ (Tab. I, Fig. 1a). ED did not change much during the ten-year period, but there was a slight general increase in LD, although with a dip in the penultimate year. There was no significant difference between years with respect to either LD or ED. Both earlywood width (EW) and latewood width (LW) decreased by about $50 \%$ during the 10 -year period (Fig. 1b). Breeding values (obtained from the ASReml runs) for ED increased on average slowly but steadily with increasing age, but the different parents developed to some extent differently. There were larger differences in breeding value for LD than $\mathrm{ED}$, and there was a considerable increase at ring number 1617, but a drop during the penultimate year (Fig. 2a). If LW was included as a covariate, the reduction also occurred during the last year (see Fig. B, online material only ${ }^{1}$ ). The amplitude between maximum and minimum breeding values relative to the mean values tended to increase with increasing ring number for ED, while it decreased for LD (Figs. 2b and 2c). For ring number 21 the difference was of similar size for ED and LD, ca. $6 \%$.

During the 10-year period, the heritability for ED increased from 0.08 in the first years to $0.20-0.25$, while it decreased for LD from approximately 0.22 to $0.10-0.15$ (Tab. Ia-Ib, Fig. 3a). In both cases, at annual ring number 17 there appeared to be some stabilising of the heritability, although the annual variation was large. The genetic coefficients of variation ranged between $3 \%$ and $6 \%$ for both ED and LD, and the trend mirrored the heritability, with an increase for ED and a decrease for LD (Fig. 3b). Analyses incorporating the covariate changed neither the heritabilities nor the genetic coefficients of variation. EW and LW had heritabilities below 0.10 during the whole period (Fig. 3a). Heritability for total earlywood density and latewood density over the ten years (EDtot and LDtot) was 0.25 and 0.22 , respectively (Tab. III).

\footnotetext{
${ }^{1}$ Figures $\mathrm{A}$ and $\mathrm{B}$, and Table A are material available online only at www.afs-journal.org.
} 
Table I. Results of analyses of earlywood and latewood densities (ED and LD, respectively) on a yearly basis. Mean density (mv), the number of analysed samples (trees) for each annual ring $\left(n_{\mathrm{yr}}\right)$, phenotypic variances $\left(\sigma_{\mathrm{P}}^{2}\right)$, heritability $\left(h^{2}\right)$, genetic coefficient of variation $\left(C V_{\mathrm{A}}\right)$, and genetic, environmental and phenotypic correlations $\left(r_{\mathrm{A}}, r_{\mathrm{E}}\right.$ and $r_{\mathrm{P}}$, respectively) with earlywood width (EW and LW, respectively), tree height (H01) and stem diameter (D01). (a) Earlywood density, (b) latewood density.

Table Ia. Earlywood density

\begin{tabular}{|c|c|c|c|c|c|c|c|c|}
\hline \multirow{2}{*}{ Ring number from pith } & & & & & & \multicolumn{3}{|c|}{ ED-EW } \\
\hline & $\mathrm{Mv}$ & $n_{\mathrm{yr}}$ & $\sigma_{\mathrm{p}}^{2}\left(\mathrm{x} 10^{-3}\right)$ & $h^{2}$ & $C V_{A}(\%)$ & $r_{\mathrm{A}}$ & $r_{\mathrm{E}}$ & $r_{\mathrm{P}}$ \\
\hline 12 & 0.345 & 878 & 1.42 & $0.083 \pm 0.040$ & 3.12 & $-0.31 \pm 0.33$ & $-0.35 \pm 0.032$ & $-0.35 \pm 0.032$ \\
\hline 13 & 0.334 & 995 & 1.16 & $0.14 \pm 0.051$ & 3.86 & $-0.28 \pm 0.27$ & $-0.22 \pm 0.033$ & $-0.23 \pm 0.033$ \\
\hline 14 & 0.342 & 912 & 1.17 & $0.21 \pm 0.066$ & 4.62 & $-0.49 \pm 0.23$ & $-0.19 \pm 0.036$ & $-0.21 \pm 0.036$ \\
\hline 15 & 0.351 & 955 & 1.30 & $0.16 \pm 0.054$ & 4.24 & $-0.57 \pm 0.24$ & $-0.20 \pm 0.035$ & $-0.21 \pm 0.035$ \\
\hline 16 & 0.361 & 1127 & 1.47 & $0.18 \pm 0.057$ & 4.51 & $-0.55 \pm 0.22$ & $-0.15 \pm 0.034$ & $-0.17 \pm 0.034$ \\
\hline 17 & 0.355 & 1307 & 1.33 & $0.25 \pm 0.066$ & 5.13 & $-0.96 \pm 0.11$ & $-0.23 \pm 0.031$ & $-0.28 \pm 0.031$ \\
\hline 18 & 0.359 & 1308 & 1.28 & $0.26 \pm 0.068$ & 5.12 & $-0.66 \pm 0.18$ & $-0.22 \pm 0.030$ & $-0.25 \pm 0.031$ \\
\hline 19 & 0.356 & 1384 & 1.26 & $0.24 \pm 0.064$ & 4.89 & $-0.63 \pm 0.17$ & $-0.28 \pm 0.029$ & $-0.30 \pm 0.029$ \\
\hline 20 & 0.354 & 1400 & 1.28 & $0.27 \pm 0.069$ & 5.26 & $-0.58 \pm 0.18$ & $-0.31 \pm 0.029$ & $-0.33 \pm 0.029$ \\
\hline 21 & 0.360 & 1258 & 1.36 & $0.20 \pm 0.057$ & 4.63 & $-0.46 \pm 0.21$ & $-0.25 \pm 0.03$ & $-0.26 \pm 0.031$ \\
\hline
\end{tabular}

\begin{tabular}{|c|c|c|c|c|c|c|}
\hline \multirow{2}{*}{ Ring number from pith } & \multicolumn{3}{|c|}{ ED-H01 } & \multicolumn{3}{|c|}{ ED-D01 } \\
\hline & $r_{\mathrm{A}}$ & $r_{\mathrm{E}}$ & $r_{\mathrm{P}}$ & $r_{\mathrm{A}}$ & $r_{\mathrm{E}}$ & $r_{\mathrm{P}}$ \\
\hline 12 & $-0.077 \pm 0.21$ & $0.11 \pm 0.036$ & $0.087 \pm 0.041$ & $-0.36 \pm 0.23$ & $-0.066 \pm 0.036$ & $-0.087 \pm 0.037$ \\
\hline 13 & $-0.068 \pm 0.21$ & $-0.0095 \pm 0.0035$ & $-0.016 \pm 0.039$ & $-0.21 \pm 0.24$ & $-0.016 \pm 0.034$ & $-0.16 \pm 0.35$ \\
\hline 14 & $-0.019 \pm 0.22$ & $-0.0032 \pm 0.036$ & $-0.005 \pm 0.041$ & $-0.32 \pm 0.23$ & $-0.13 \pm 0.036$ & $-0.14 \pm 0.37$ \\
\hline 15 & $-0.066 \pm 0.22$ & $-0.0060 \pm 0.036$ & $-0.013 \pm 0.040$ & $-0.37 \pm 0.23$ & $-0.18 \pm 0.035$ & $-0.19 \pm 0.36$ \\
\hline 16 & $-0.063 \pm 0.23$ & $0.1937 \pm 0.032$ & $0.17 \pm 0.036$ & $-0.32 \pm 0.26$ & $0.079 \pm 0.034$ & $0.056+0.035$ \\
\hline 17 & $-0.31 \pm 0.22$ & $0.0457 \pm 0.032$ & $0.013 \pm 0.036$ & $-0.60 \pm 0.21$ & $-0.085 \pm 0.032$ & $-0.11 \pm 0.033$ \\
\hline 18 & $-0.28 \pm 0.20$ & $0.0438 \pm 0.032$ & $0.009 \pm 0.036$ & $-0.67 \pm 0.18$ & $-0.075 \pm 0.032$ & $-0.11 \pm 0.033$ \\
\hline 19 & $-0.013 \pm 0.23$ & $0.084 \pm 0.031$ & $0.074 \pm 0.034$ & $-0.35 \pm 0.25$ & $-0.019 \pm 0.031$ & $-0.036 \pm 0.032$ \\
\hline 20 & $-0.36 \pm 0.20$ & $-0.073 \pm 0.031$ & $-0.10 \pm 0.035$ & $-0.49 \pm 0.21$ & $-0.19 \pm 0.030$ & $-0.21 \pm 0.031$ \\
\hline 21 & $-0.15 \pm 0.24$ & $0.017 \pm 0.032$ & $0.003 \pm 0.034$ & $-0.49 \pm 0.24$ & $-0.080 \pm 0.032$ & $-0.10 \pm 0.032$ \\
\hline
\end{tabular}

Table Ib. Latewood density

\begin{tabular}{|c|c|c|c|c|c|c|c|c|c|}
\hline \multirow{2}{*}{ Ring number from pith } & \multirow[b]{2}{*}{$\mathrm{Mv}$} & \multirow[b]{2}{*}{$n_{\mathrm{yr}}$} & \multirow[b]{2}{*}{$\sigma_{\mathrm{p}}^{2}$} & \multirow{2}{*}{\multicolumn{2}{|c|}{$h^{2}$}} & \multirow[b]{2}{*}{$C V_{\mathrm{A}}(\%)$} & \multicolumn{3}{|c|}{ LD-LW } \\
\hline & & & & & & & $r_{\mathrm{A}}$ & $r_{\mathrm{E}}$ & $r_{\mathrm{P}}$ \\
\hline 12 & 0.689 & 901 & 7.27 & 0.2 & $=0.066$ & 5.67 & $-0.14 \pm 0.37$ & $-0.25 \pm 0.034$ & $-0.24 \pm 0.034$ \\
\hline 13 & 0.678 & 1007 & 7.77 & 0.2 & $=0.062$ & 6.03 & $-0.11 \pm 0.29$ & $-0.37 \pm 0.030$ & $-0.35 \pm 0.031$ \\
\hline 14 & 0.689 & 923 & 7.46 & 0.2 & $=0.070$ & 6.35 & $-0.14 \pm 0.27$ & $-0.29 \pm 0.034$ & $-0.28 \pm 0.035$ \\
\hline 15 & 0.695 & 970 & 6.91 & 0.1 & $=0.060$ & 5.35 & $0.039 \pm 0.28$ & $-0.34 \pm 0.034$ & $-0.32 \pm 0.035$ \\
\hline 16 & 0.774 & 1130 & 10.32 & 0.12 & $=0.046$ & 4.77 & $-0.071 \pm 0.42$ & $-0.19 \pm 0.034$ & $-0.18 \pm 0.034$ \\
\hline 17 & 0.765 & 1309 & 9.43 & 0.1 & $=0.042$ & 4.28 & $0.061 \pm 0.39$ & $-0.21 \pm 0.032$ & $-0.20 \pm 0.032$ \\
\hline 18 & 0.767 & 1310 & 8.13 & 0.1 & $=0.049$ & 4.70 & $-0.051 \pm 0.26$ & $-0.23 \pm 0.031$ & $-0.22 \pm 0.032$ \\
\hline 19 & 0.786 & 1385 & 8.45 & 0.1 & $=0.041$ & 3.92 & $0.46 \pm 0.31$ & $-0.12 \pm 0.032$ & $-0.095 \pm 0.032$ \\
\hline 20 & 0.720 & 1400 & 10.24 & 0.1 & $=0.048$ & 5.46 & $0.52 \pm 0.41$ & $-0.15 \pm 0.031$ & $-0.13 \pm 0.031$ \\
\hline 21 & 0.736 & 1293 & 11.82 & 0.09 & \pm 0.039 & 4.53 & $0.42 \pm 0.34$ & $0.093 \pm 0.032$ & $0.10 \pm 0.032$ \\
\hline \multirow{2}{*}{ Ring number from pith } & \multicolumn{6}{|c|}{ LD-H01 } & \multicolumn{3}{|c|}{ LD-D01 } \\
\hline & \multicolumn{2}{|c|}{$r_{\mathrm{A}}$} & \multicolumn{2}{|c|}{$r_{\mathrm{E}}$} & \multicolumn{2}{|c|}{$r_{\mathrm{P}}$} & $r_{\mathrm{A}}$ & $r_{\mathrm{E}}$ & $r_{\mathrm{P}}$ \\
\hline 12 & \multicolumn{2}{|c|}{$-0.15 \pm 0.27$} & \multicolumn{2}{|c|}{$0.0065 \pm 0.036$} & \multicolumn{2}{|c|}{$-0.006 \pm 0.038$} & $-0.60 \pm 0.27$ & $-0.050 \pm 0.036$ & $-0.074 \pm 0.036$ \\
\hline 13 & \multicolumn{2}{|c|}{$-0.18 \pm 0.22$} & \multicolumn{2}{|c|}{$-0.020 \pm 0.035$} & \multicolumn{2}{|c|}{$-0.036 \pm 0.038$} & $-0.36 \pm 0.24$ & $-0.092 \pm 0.035$ & $-0.11 \pm 0.035$ \\
\hline 14 & \multicolumn{2}{|c|}{$0.082 \pm 0.22$} & \multicolumn{2}{|c|}{$0.066 \pm 0.036$} & \multicolumn{2}{|c|}{$0.068 \pm 0.041$} & $-0.24 \pm 0.24$ & $-0.008 \pm 0.037$ & $-0.025 \pm 0.038$ \\
\hline 15 & \multicolumn{2}{|c|}{$-0.11 \pm 0.22$} & \multicolumn{2}{|c|}{$0.094 \pm 0.036$} & \multicolumn{2}{|c|}{$0.072 \pm 0.039$} & $-0.35 \pm 0.24$ & $-0.008 \pm 0.036$ & $-0.015 \pm 0.037$ \\
\hline 16 & \multicolumn{2}{|c|}{$-0.16 \pm 0.21$} & \multicolumn{2}{|c|}{$0.063 \pm 0.034$} & \multicolumn{2}{|c|}{$0.038 \pm 0.038$} & $-0.41 \pm 0.23$ & $-0.043 \pm 0.057$ & $-0.068 \pm 0.035$ \\
\hline 17 & \multicolumn{2}{|c|}{$-0.37 \pm 0.18$} & \multicolumn{2}{|c|}{$-0.057 \pm 0.032$} & \multicolumn{2}{|c|}{$-0.098 \pm 0.038$} & $-0.44 \pm 0.20$ & $-0.15 \pm 0.032$ & $-0.17 \pm 0.033$ \\
\hline 18 & \multicolumn{2}{|c|}{$-0.21 \pm 0.19$} & $-0.050 \pm$ & .032 & -0.071 & 0.038 & $-0.45 \pm 0.20$ & $-0.14 \pm 0.031$ & $-0.16 \pm 0.033$ \\
\hline 19 & $-0.20 \pm 0$ & & $-0.091 \pm$ & .031 & -0.11 & 0.037 & $-0.45 \pm 0.20$ & $-0.18 \pm 0.030$ & $-0.20 \pm 0.032$ \\
\hline 20 & $-0.28 \pm 0$ & & $-0.071 \pm$ & .031 & -0.10 & 0.038 & $-0.49 \pm 0.19$ & $-0.20 \pm 0.030$ & $-0.22 \pm 0.032$ \\
\hline 21 & $-0.22 \pm 0$ & & $-0.070 \pm$ & .032 & -0.087 & 0.036 & $-0.43 \pm 0.21$ & $-0.17 \pm 0.031$ & $-0.19 \pm 0.032$ \\
\hline
\end{tabular}




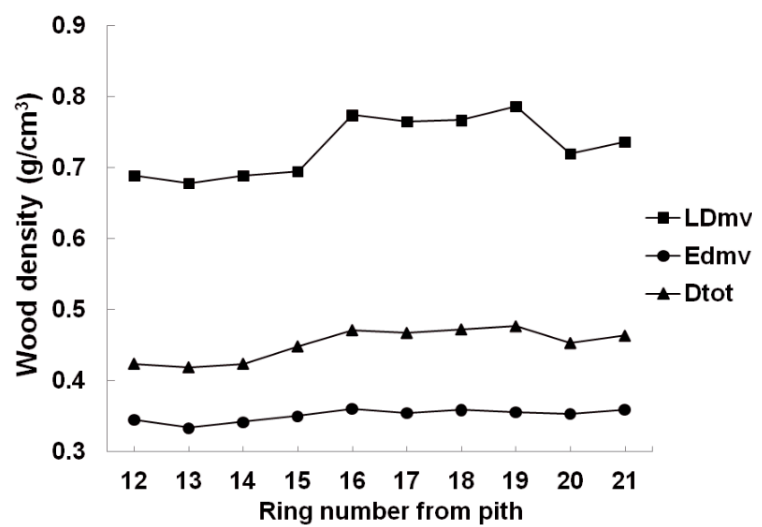

(a)

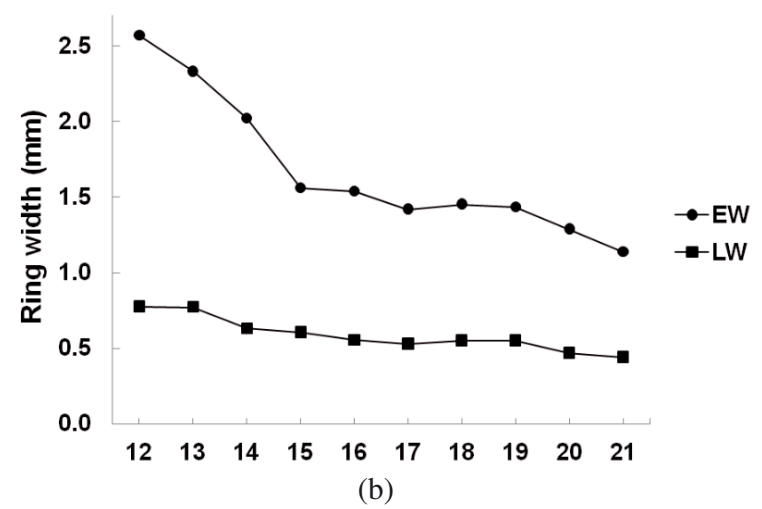

Figure 1. (a) Average densities for earlywood (EDmv) and latewood (LDmv), and total (Dtot) for each annual ring $\left(\mathrm{g} \cdot \mathrm{cm}^{-3}\right)$. (b) Average widths of the earlywood (EW) and latewood (LW) ring sections $(\mathrm{mm})$, and the quotients $\mathrm{ED} / \mathrm{EW}$ and $\mathrm{LD} / \mathrm{LW}\left(\mathrm{g} \cdot \mathrm{cm}^{-3} \times \mathrm{mm}^{-1}\right)$.

The genetic correlations between annual rings nearly always exceeded 0.7 for both ED and LD in different years (Tab. IIa, see also Tab. Aa-Ab, online material only ${ }^{1}$. Attempts to make use of a banded pattern, e.g. a pattern showing equal correlations between adjacent years, were not successful for $\mathrm{ED}$, while banded correlations were present for LD, and the most informative gave genetic correlations between 0.86 and 0.97 (see Tab. Ac, online material only ${ }^{1}$ ).

Genetic correlations between ED and LD for individual years were high, with $r_{\mathrm{A}}$ generally exceeding ca. 0.7 , except for density correlations between recently formed earlywood and early formed latewood, i.e. $\Delta$ year 5-9 in Table IIb and the upper right part of Table Ad. In this case $r_{\mathrm{A}}$ was between 0.4 and 0.5. The genetic correlations between ED and EW were negative, generally $r_{\mathrm{A}}=-0.3$ to -1.0 (Tab. Ia); it was not possible to discern a genetic correlation between LD and LW because of the large standard errors (Tab. Ib). The phenotypic correlations $r_{\mathrm{P}}$ between $\mathrm{ED}$ and $\mathrm{EW}$ and between $\mathrm{LD}$ and LW were generally negative $\left(r_{\mathrm{P}}=-0.1\right.$ to -0.35$)$; between ED and $\mathrm{LD}$ this correlation was positive and highest between adjacent years (low $\Delta$ year in Tab. II and close to the diagonal in $\mathrm{Tab} . \mathrm{Ae}$ ). In this case the correlations were generally between 0.5 and 0.6 .

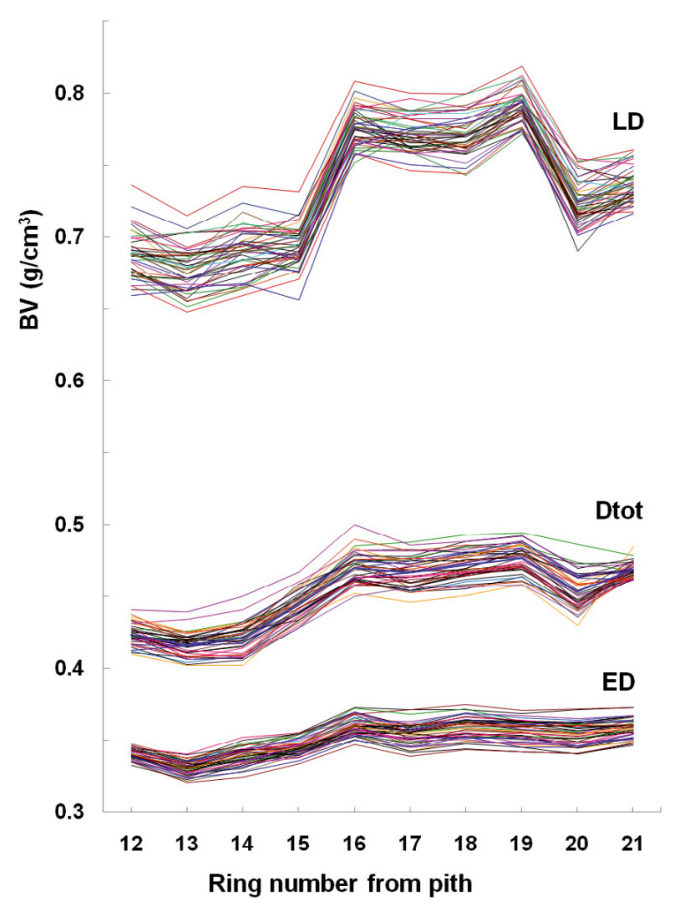

(a)

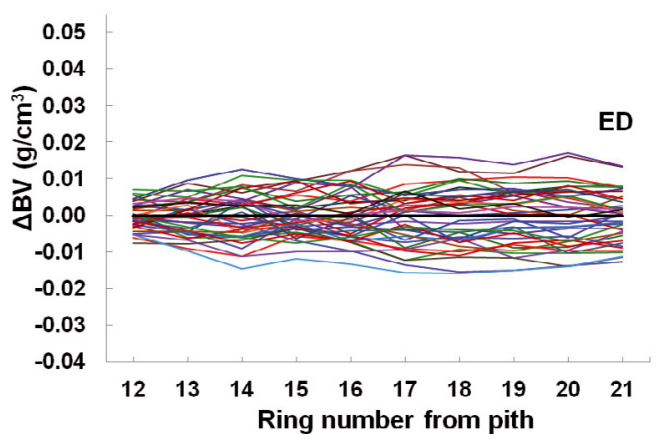

(b)

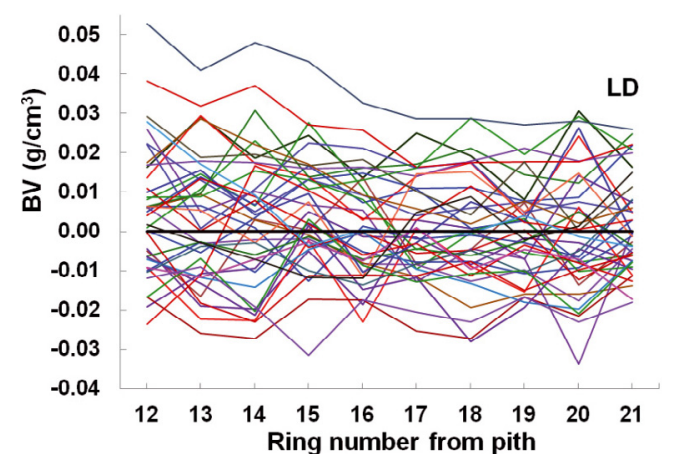

(c)

Figure 2. Changes in total breeding values (BV) in $\mathrm{g} \cdot \mathrm{cm}^{-3}$ and their deviations from mean values over the 10 years (no covariate). (a) Total breeding values of the 40 parents (also for total density, Dtot), (b) deviation from the mean of earlywood density (ED) for the 40 parents, and (c) deviation from the mean of latewood density (LD). For total breeding values of the 40 parents estimated with the ring width as a covariate, see Figure B, online material. 


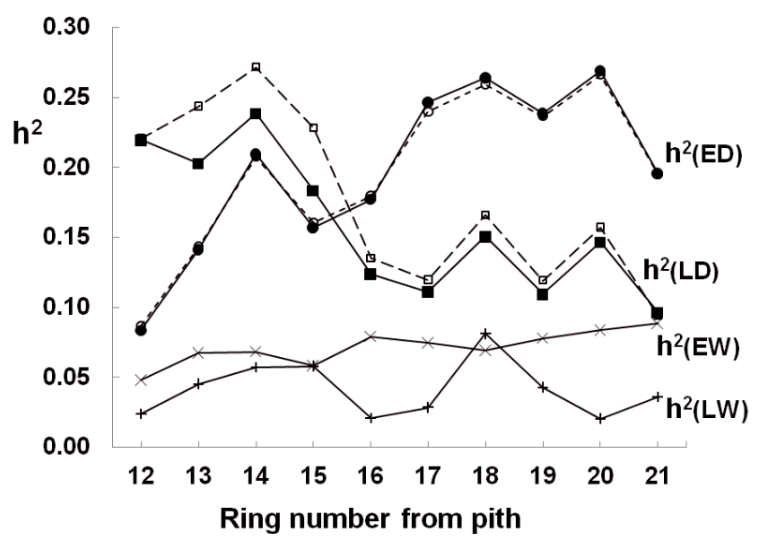

(a)

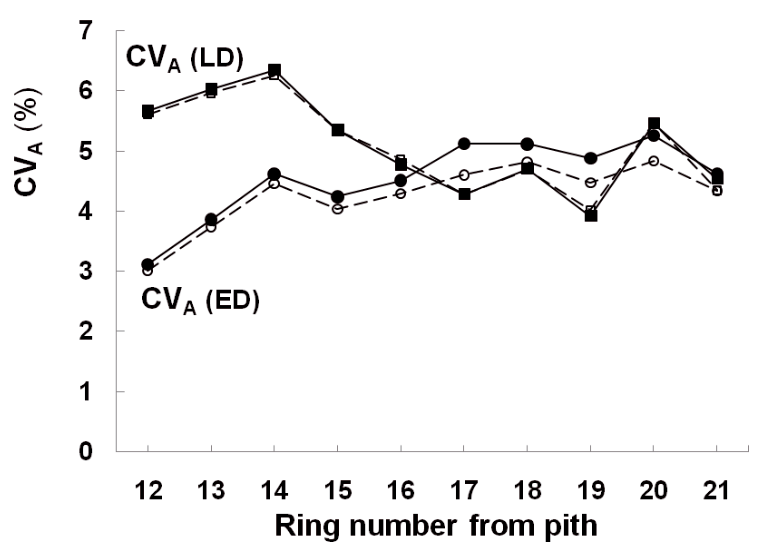

(b)

Figure 3. Changes in: (a) heritability $\left(h^{2}\right)$ and (b) genetic coefficient of variation $\left(C V_{\mathrm{A}}\right)$ for earlywood and latewood density and total density (ED and LD). For heritability, earlywood and latewood ring widths are also given (EW and LW). Solid line: no covariate, broken line: the width of the corresponding ring section used as a covariate.

Height (H01) exhibited a weak negative genetic correlation with ED, with $r_{\mathrm{A}}$ often close to zero (Tab. I), and a weak correlation with $\mathrm{LD}\left(r_{\mathrm{A}}\right.$ is higher but has large standard errors, Tab. I). In addition, stem diameter (D01) showed negative genetic correlations with $\mathrm{ED}$ and $\mathrm{LD}\left(r_{\mathrm{A}}=-0.21\right.$ to -0.67 ; Tab. I) (for these correlations, see also the online material ${ }^{1}$, Figs. Aa- $\mathrm{Ad}^{1}$ ). The influence of the covariate was also very limited in this case. When considering the growth traits and average density of the 10 annual rings (EDtot and LDtot, respectively), the genetic correlations were negative. For EDtot they were $r_{\mathrm{A}}=-0.31$ and $r_{\mathrm{A}}=-1.10$ with $\mathrm{H} 01$ and D01, respectively, and for LDtot they were $r_{\mathrm{A}}=-0.11$ and $r_{\mathrm{A}}=-0.96$, respectively (Tab. III). The phenotypic correlations were generally low and no covariate effect was observed (data not shown). Between EDtot and LDtot the genetic and environmental correlations were strongly positive $\left(r_{\mathrm{A}}=0.72\right.$ and $r_{\mathrm{E}}=0.57$, respectively). The heritability for height was 0.29 and for stem diameter 0.10 , and the genetic correlation between them was 0.42 (Tab. III). Lower heritability for stem diameter than for height is normal, and one reason is uneven competition due to irregular spacing caused by early mortality.

\section{DISCUSSION}

There was no substantial change in the average ED throughout the 10-year period, while LD increased, albeit with a drop in the penultimate year (Tab. I and Fig. 1a). When whole ring density was analysed for the same data (Fries and Ericsson, 2006), using the total ring width of the corresponding annual ring as a covariate eliminated the negative genetic correlation between height and wood density, and the environmental correlation between density and stem diameter. However, the negative genetic correlation between density and stem diameter remained. In the present study, with separate analyses of earlywood and latewood, none of the corresponding correlations changed when the analysis incorporated a covariate. Since data for all annual rings was only available for a few individuals, the standard errors were, however, rather high (Tab. III). In a study of whole ring density by $\mathrm{Li}$ and $\mathrm{Wu}$ (2005), the effect of introducing the ring area as a covariate when analysing correlations and heritabilities was that the high variability disappeared. The variation without a covariate could be a consequence of annual variation in the relationship between earlywood and latewood becoming confounded with densities when analysing whole ring density rather than earlywood and latewood separately. Thus, the lack of influence of the width of the corresponding wood section is consistent with the hypothesis that separating earlywood and latewood in density analyses reduces the effect of annual variation in radial growth.

We obtained clear negative genetic and phenotypic correlations between ED and EW $\left(r_{\mathrm{A}}=-0.28\right.$ to -0.96 and $r_{\mathrm{P}}=-0.17$ to -0.35 ; Tab. Ia). For LD and LW the phenotypic correlation was negative $\left(r_{\mathrm{P}}=-0.095\right.$ to -0.35$)$, but because of high standard errors it was impossible to state a genetic correlation (Tab. Ib). In Pinus radiata there were lower genetic correlations for ED and LD when examining the area of the earlywood and latewood sections instead of the widths $\left(r_{\mathrm{A}}=-0.06\right.$ to 0.04 ; Zamudi et al., 2005).

Like the ED-EW and LD-LW relationships, there were clear negative genetic correlations between both ED and stem diameter (D01) and between LD and D01 (Tab. Ia, Ib and Figs. $\mathrm{Ab}$ and $\mathrm{Ad}$, online material only ${ }^{1}$ ). Similarly, various studies have shown that the whole ring density and growth is negatively correlated; see, e.g., Vargas-Hernandez (1991), Hannrup et al. (2000), Fries and Ericsson (2006), and Li and Wu (2005). Although Hodge and Purnell (1993), however, found both negative and positive genetic correlations, the frequent negative genetic correlations between densities and growth traits demonstrate the difficulties associated with combining good growth with sufficiently high density. However, the genetic correlations vary considerably and breeding values for different parents develop after diverging paths (Figs. 2a$2 \mathrm{c}$ ), indicating that some trees have less negative or even positive genetic correlations and that breeding improvement may be possible.

Breeding values for ED increased slowly but steadily with increasing ring number from the pith, while for LD they increased but showed larger between-years differences (Fig. 2a). The amplitude of the relative breeding value for ED tended to increase and was ca. $6 \%$ of the average by the end of the period 
Table II. Average genetic, environmental and phenotypic correlations $\left(r_{A}, r_{E}\right.$ and $r_{P}$, respectively) between earlywood and latewood densities for different years. $\Delta$ ring indicates the number of years between each of the density estimates. For each separate correlation including their standard errors, see Table Aa-Ae online material only ${ }^{1}$. (a) Within the same wood type, i.e. for $\Delta$ ring 1 , the averages of the correlation coefficients for the regressions between ring 12 and 13, 13 and 14 , etc., up to ring 20 to 21 (nine values) are used, for $\Delta$ ring 8 , the average correlations between ring 12 and 20 and between ring 13 and 21 (two values) are used, and for $\Delta$ ring 9, only one correlation is included, between ring 12 and 21. (b) Between wood types. The corresponding average correlations with $\Delta$ ring estimated by ring number for ED minus LD.

(a) Between the same woodtype.

\begin{tabular}{lcccccc}
\hline \multicolumn{3}{c}{ ED-ED } & \multicolumn{3}{c}{ LD-LD } \\
\hline$\Delta$ ring & $r_{\mathrm{A}}$ & $r_{\mathrm{P}}$ & $r_{\mathrm{E}}$ & $r_{\mathrm{A}}$ & $r_{\mathrm{P}}$ & $r_{\mathrm{E}}$ \\
\hline 1 & 0.95 & 0.59 & 0.56 & 0.96 & 0.78 & 0.76 \\
2 & 0.91 & 0.61 & 0.58 & 0.94 & 0.75 & 0.75 \\
3 & 0.91 & 0.57 & 0.55 & 0.83 & 0.70 & 0.68 \\
4 & 0.86 & 0.44 & 0.41 & 0.88 & 0.71 & 0.69 \\
5 & 0.79 & 0.54 & 0.52 & 0.82 & 0.66 & 0.65 \\
6 & 0.71 & 0.47 & 0.45 & 0.79 & 0.67 & 0.66 \\
7 & 0.74 & 0.50 & 0.48 & 0.82 & 0.66 & 0.65 \\
8 & 0.57 & 0.40 & 0.51 & 0.83 & 0.64 & 0.63 \\
9 & 0.63 & 0.35 & 0.34 & 0.76 & 0.60 & 0.59
\end{tabular}

(b) Between wood types.

\begin{tabular}{lccccccc}
\hline \multicolumn{4}{c}{ ED minus LD } & \multicolumn{4}{c}{ ED minus LD } \\
\hline$\Delta$ ring & $r_{\mathrm{A}}$ & $r_{\mathrm{P}}$ & $r_{\mathrm{E}}$ & $\Delta$ ring & $r_{\mathrm{A}}$ & $r_{\mathrm{P}}$ & $r_{\mathrm{E}}$ \\
\hline 0 & 0.86 & 0.54 & 0.51 & & & & \\
1 & 0.78 & 0.44 & 0.41 & -1 & 0.86 & 0.46 & 0.42 \\
2 & 0.71 & 0.44 & 0.42 & -2 & 0.88 & 0.43 & 0.39 \\
3 & 0.64 & 0.40 & 0.38 & -3 & 0.88 & 0.39 & 0.36 \\
4 & 0.62 & 0.43 & 0.42 & -4 & 0.87 & 0.36 & 0.32 \\
5 & 0.50 & 0.43 & 0.42 & -5 & 0.92 & 0.37 & 0.33 \\
6 & 0.48 & 0.45 & 0.45 & -6 & 0.84 & 0.29 & 0.25 \\
7 & 0.48 & 0.44 & 0.44 & -7 & 0.90 & 0.38 & 0.35 \\
8 & 0.45 & 0.41 & 0.41 & -8 & 0.86 & 0.29 & 0.25 \\
9 & 0.46 & 0.37 & 0.36 & -9 & 1.10 & 0.28 & 0.25 \\
\hline
\end{tabular}

(Fig. 2b). For LD the final amplitude was about the same percentage, but here there was a decreasing trend (Fig. 2c). One possible reason for the decrease in $\mathrm{LD}$ in the penultimate year is the narrow latewood section making the delineation between earlywood and latewood rather difficult. If some of the earlywood is included, this will reduce the calculated density. This explanation is supported by the greater phenotypic variance recorded for $\mathrm{LD}$ of the outermost rings (Tab. I).

The heritability exhibited an increasing trend with age for ED, but a decreasing trend for LD (Fig. 3a). Similar trends have also been recognised in Pinus pinaster by Gaspar et al. (2008) up to ring number 11. In our study, however, heritabilities seemed to stabilise at ring number $16-17$, with a value of ca. 0.25 for ED and $0.10-0.15$ for LD. At this age EW and LW also stabilised (Fig. 1b). This phenomenon was also recorded for ring density and ring width by $\mathrm{Li}$ and $\mathrm{Wu}$ (2005). Furthermore, in the previous whole ring density analysis of the material examined here (Fries and Ericsson, 2006), heritability was constant but fluctuated during the 10-year pe- riod. Including the covariate in the present study had no final effect on either the heritability or the coefficient of variation (Figs. 3a-3b). Heritabilities for EDtot and LDtot were 0.25 and 0.26 , respectively (Tab. III), and this was similar to or slightly lower than heritabilities for earlywood, latewood and total densities recorded in many other studies, e.g. Fries (1986) studying Pinus contorta; Hannrup et al. (2000) and Fries and Ericsson (2006) studying Scots pine; Gwaze et al. (2002) studying Pinus taeda; Ivkovich et al. (2002) studying Picea engelmannia and Picea glauca; $\mathrm{Li}$ and $\mathrm{Wu}(2005)$ and Zamudi et al. (2005) studying Pinus radiata; Bouffier at al. (2008a; 2008b) studying Pinus pinaster; and Ukrainetz (2008) studying Pseudotsuga menziesii. An additional general pattern is that the estimated heritabilities for ED and LD are of similar size, although Louzada et al. (2002), Bouffier et al. (2008b) and Ukrainetz (2008) recorded a higher value for ED than LD.

The stabilisation of heritabilities (Fig. 3a), coefficients of variation (Fig. 3b) and breeding values (Fig. 2a) at around annual ring 17 corresponds to the age when the transition from juvenile wood to mature wood is thought to occur (see, e.g., Burdon et al., 2004 and a literature review in Kučera 1994). Therefore, our results do not contradict this suggested age for the change from juvenile to mature wood.

The genetic correlations between ED and LD of the same or adjacent annual rings was above 0.7 (low $\Delta$ year in Tab. IIb), and the standard errors were low (Tab. Ad, online material only $\left.{ }^{1}\right)$. The genetic correlation between EDtot and LDtot was 0.72 (Tab. III). These findings indicate that selecting for high ED entails little risk of reductions in LD, or vice versa, in accordance with Hodge and Purnell (1993). However, low genetic correlations between the density of recently formed earlywood and early formed latewood (Tab. IId) indicate that selection based on latewood density before mature age may be less effective, while using ED as a selection criterion at young ages may be very effective for achieving high density when the trees are older.

Like $C V_{\mathrm{A}}$, a higher final heritability for $\mathrm{ED}$ than for $\mathrm{LD}$ for the most recently formed annual rings and increasing amplitude in the relative breeding value indicate a stronger genetic influence on ED than on LD, especially with increasing age. The large standard errors for correlations including LD are probably partly due to difficulties in measuring LD using the technique employed in this study, and make ED a somewhat safer selection criterion than LD if only one of them is to be chosen.

\section{CONCLUSIONS}

The higher final heritabilities for ED than for LD (Fig. 3a), the equal genetic coefficient of variation (Fig. 3b), and the increasing amplitude of the relative breeding values for ED (Fig. 2b) indicate that ED is a somewhat safer selection criterion than LD. This is supported by the higher genetic correlation between earlywood formed at a young age and latewood formed at an advanced age than between early formed latewood and recently formed earlywood (Tab. II; see also Tab. Ad, online material only ${ }^{1}$ ). However, the generally strong positive genetic correlation between ED and LD for the same 
Table III. Correlations including standard errors of the relationship between average densities for all 10 annual rings (EDtot and LDtot), height growth (H01) and stem diameter (D01). Heritabilities $\left(h^{2}\right)$ along the emboldened diagonal, additive genetic correlation $r_{\mathrm{A}}$ above the diagonal and environmental correlation $r_{\mathrm{E}}$ below. In the right part is phenotypic variance $\left(\sigma_{\mathrm{P}}^{2}\right)$, genetic variance $\left(\sigma_{\mathrm{A}}^{2}\right)$, genetic coefficient of variation and the mean value. For EDtot and LDtot; data from the 370 trees with observations for all annual rings, for height and stem diameter; data from 1243 trees in total.

\begin{tabular}{|c|c|c|c|c|c|c|c|c|}
\hline Trait & EDtot & LDtot & H01 & D01 & $\sigma_{P}^{2}$ & $\sigma_{A}^{2}$ & $\mathrm{CV}_{A}$ & Mean \\
\hline$\overline{\text { EDtot }}$ & $0.25 \pm 0.098$ & $0.72 \pm 0.168$ & $-0.31 \pm 0.29$ & $-1.10 \pm 0.71$ & $2.01 \pm 0.16\left(\mathrm{~g} \cdot \mathrm{cm}^{-3}\right)^{2}$ & $0.52 \pm 0.22\left(\mathrm{~g} \cdot \mathrm{cm}^{-3}\right)^{2}$ & $2.1 \%$ & $0.347 \mathrm{~g} \cdot \mathrm{cm}^{-3}$ \\
\hline LDtot & $0.57 \pm 0.037$ & $0.22 \pm 0.095$ & $-0.11 \pm 0.31$ & $-0.96 \pm 0.62$ & $4.2 \pm 0.34\left(\mathrm{x} 10^{-3}\right)\left(\mathrm{g} \cdot \mathrm{cm}^{-3}\right)^{2}$ & $0.97 .2 \pm 0.31\left(\mathrm{x} 10^{-3}\right)\left(\mathrm{g} \cdot \mathrm{cm}^{-3}\right)^{2}$ & $4.2 \%$ & $0.737 \mathrm{~g} \cdot \mathrm{cm}^{-3}$ \\
\hline H01 & $0.065 \pm 0.056$ & $0.040 \pm 0.056$ & $0.29 \pm 0.070$ & $0.42 \pm 0.18$ & $128.7 \pm 6.68(\mathrm{dm})^{2}$ & $36.5 \pm 10.1(\mathrm{dm})^{2}$ & $5.4 \%$ & $111.6 \mathrm{dm}$ \\
\hline D01 & $-0.064 \pm 0.054$ & $-0.076 \pm 0.055$ & $0.64 \pm 0.017$ & $\mathbf{0 . 1 0} \pm \mathbf{0 . 0 3 6}$ & $1028.6 \pm 43.0(\mathrm{~mm})^{2}$ & $107.1 \pm 39.2(\mathrm{~mm})^{2}$ & $6.7 \%$ & $154.2 \mathrm{~mm}$ \\
\hline
\end{tabular}

or similar annual rings, and between EDtot and LDtot, indicate that selection for ED will result in an increase in LD. Therefore, earlywood density or whole ring density could be sufficient as a predictor, and it should be included as a selection trait, if possible, in order to avoid poor density characteristics when trees are selected for good growth.

In analyses of earlywood and latewood density it is not necessary to include the width of the corresponding ring section as a covariate.

The age interval 15-20 years from the pith for transition from juvenile to mature wood as often suggested in the literature is, when considering the development of average densities, heritabilities and genetic coefficients of variation, not contradicted. It is preferable to wait until trees reach at least this age before using ED or LD as selection criteria for mature wood density. ED, however, may be used earlier.

Acknowledgements: Support for this work was provided by Föreningen Skogsträdsförädling, Uppsala, Sweden. Skogforsk (the forestry research institute of Sweden) undertook the field measurements and collected the wood samples. Johan Lindeberg and Tommy Mörling, Department of Silviculture, SLU, Umeå, Sweden, gave valuable advice during the wood analyses.

\section{REFERENCES}

Bergsten U., Lindeberg J., Rindby A., and Evans R., 2001. Batch measurements of wood density on intact or prepared drill cores using X-ray microdensiometry. Wood Sci. Tech. 35: 435-452.

Bouffier L., Charlot, C., Raffin A., Rozenberg P., and Kremer A., 2008a. Can wood density be effectively selected at early stage in maritime pine (Pinus pinaster Ait.)? Ann. For. Sci. 65: 106.

Bouffier L., Rozenberg P., Raffin A., and Kremer A., 2008b. Wood density variability in successive breeding populations of maritime pine. Can. J. For. Res. 38: 2148-2158.

Burdon R.D., Kibblewhite R.P., Walker J.C.F., Megraw R.A., Evans R., and Cown J.C., 2004. Juvenile versus mature wood: a new concept, orthogonal corewood versus outerwood, with special reference to Pinus radiata and P. taeda. For. Sci. 50: 399-415.

Cown D.J., 1992. Corewood (juvenile wood) in Pinus radiata - should we be concerned? New Zeal. J. For. Sci. 22: 87-95.

Courchene C.E., Peter G.F., and Litvay J., 2006. Cellulose microfibril angle as a determinant of paper strength and hygroexpansivity in Pinus taeda L. Wood Fibre Sci. 38: 112-120.

Evans R., Downes G., Menz D., and Stringer S., 1995. Rapid measurement of variation in tracheid transverse dimensions in a radiata pine tree. Appita 48: 134-138.

Fries A., 1986. Volume growth and wood density of plus tree progenies of Pinus contorta in two Swedish field trials. Scand. J. For. Res. 1: 403-419.
Fries A. and Ericsson T., 2006. Estimating genetic parameters for wood density of Scots pine (Pinus sylvestris L.). Silvae Genet. 55: 84-92.

Gaspar M.J., Louzada J.L., Silva M.E., Aguiar A., and Almeida M.H., 2008. Age trends in genetic parameters of wood density components in 46 half-sibling families of Pinus pinaster. Can. J. For. Res. 38: 1470-1477.

Gilmour A.R., Gogel B.J., Cullis B.R., and Thompson R., 2006. ASReml user guide release 2.0 VSN International Ltd, Hemel Hempstead, HP1 1ES, UK, 342 p.

Gwaze D.P., Harding K.J., Purnell R.C., and Bridgwater F.E., 2002. Optimum selection age in loblolly pine. Can. J. For. Res. 32: 13931399.

Hannrup B., Ekberg I., and Persson A., 2000. Genetic correlations among wood, growth capacity and stem traits in Pinus sylvestris. Scand. J. For. Res. 15: 161-170.

Hodge G.R. and Purnell R.C., 1993. Genetic parameter estimates for wood density, transition age, and radial growth in slash pine. Can. J. For. Res. 23: 1881-1891.

Ivkovich M., Namkoong G., and Koshy M., 2002. Genetic variation in wood properties of interior spruce. I. Growth, latewood percentage, and wood density. Can. J. For. Res. 32: 2116-2127.

Kempthorne O. and Curnow R.N., 1961. The partial diallel cross. Biometrics 24: 229-250.

Kučera B., 1994. A hypothesis relating current annual height increment to juvenile wood formation in Norway spruce. Wood Fiber Sci. 26: $152-167$.

Li L. and Wu H.X., 2005. Efficiency of early selection for rotation-aged growth and wood density traits in Pinus radiata. Can. J. For. Res. 35: 2019-2029.

Lindeberg J., 2001. X-ray based dendro-analyses of wood properties. Lic. Thesis, Dept. of Silviculture, Swedish Univ. Agric. Sci., Report 50: $18 \mathrm{p}$.

Louzada J.L.P.C. and Fonseca F.M.A., 2002. The heritability of wood density components in Pinus pinaster Ait. and the implications for tree breeding. Ann. For. Sci. 59: 867-873.

Steffenrem A., Saranpää P., Lundqvist S.-O., and Skrøppa T., 2007. Variation in wood properties among five full-sib families of Norway spruce (Picea abies). Ann. For. Sci. 64: 799-806.

Ukrainetz N.K., Kang K.-Y., Aitken S.N., Stoehr M., and Mansfield S.D., 2008. Heritability and phenotypic and genetic correlations of coastal Douglas-fir (Pseudotsuga menziesii) wood quality traits. Can. J. For. Res. 38: 1536-1546.

Vargas-Hernandez J. and Adams W.T., 1991. Genetic variation of wood density components in young coastal Douglas-fir: implications for tree breeding. Can J. For. Res. 21: 1801-1807.

Vargas-Hernandez J., Adams W.T., and Krahmer R.L., 1994. Family variation in age trends of wood density traits in young Coastal Douglasfir. Wood Fiber Sci. 26: 229-236.

Zamudi F., Rozenberg P., Baettig R., Vergara A., Yañez M., and Gantz C., 2005. Genetic variation of wood density components in a radiata pine progeny test located in the south of Chile. Ann. For. Sci. 62: 105-114.

Zobel B.J. and Sprague J.R., 1998. Juvenile wood in forest trees, Springer, Berlin, Heidelberg, and New York, 300 p. 